\section{WEST NORFOLK AND LYNN HOSPITAL.}

\section{CASE OF GUN-SHOT WOUND.}

By Charles Cotron, M.D., F.R.C.S., Surgeon to the Hospital.

William Allen, aged 5, admitted about five o'clock in the afternoon. The accidental discharge of a gun laden with peas, had carried away the integuments and fleshy parts of the left cheek, completely laying open the mouth, comminuting the lower jaw, and destroying also the soft parts of the same side of the neck. The accident was said to have occurred about two o'clock, whilst playing with some boys in a field seven or eight miles distant from the hospital, and it was stated that he had romited more than a pint of blood, and lost much besides.

The poor boy was breathing with the greatest difficulty, and with a loud noisy gurgling, accompanied also with a whistling sound, issuing from a hole in the upper and anterior part of the thyroid cartilage, .where it had been grazed and wounded; the pulse was extremely feeble, the surface of the body cold, and the countenance livid and betraying much distress. Fearing lest a piece of the lower ramus of the jaw, which lay within the mouth, having only a slight membranous attachment, might partly impede the breathing, I proceeded to remove it, and with the cutting forceps, divested the jaw remaining, in front, close to the symphysis, and behiud, on a level with the ascending ramus, of its irregularly fractured ends. The wound in the thyroid cartilage, was as much as possible exposed, and as the least obstruction, still more impeded respiration, it was enlarged by a portion of it being removed, giving exit to large quantities of red frothy fluid. 'The unsightly and charred fleshy parts were lightly covered with lint, and an enema of brandy and beef-tea was administered. The boy experienced little or no relief, but in a few minutes after a convulsive struggle $e x$ pired, and was pronounced to be dead, and the poor mother, who had been a witness of our little patient's sufferings, left the bed-side in a state of the greatest affliction.

Deliberating for awhile I dispatched Mr. Rackham, the resident medical officer, to the surgery for a narrow bistoury and a tracheal tube; all this occupied perhaps from two to three minutes. On his return, by a direct incision from above the sternum upwards, attended with a trifling hæemorrhage, the trachea was laid bare, the rings of which to the required extent were instantly divided, and the usual curved silver tube introduced. An attempt was made by ineans of a syringe to exhaust the trachea and bronchi of the frothy mucus, which was present in great abundance; this proving ineffectual, I placed iny lips over the tube, and by suction I succeeded in doing so. I then steadily, still applying my mouth to the tube, commenced inflating the lungs, and persevered for some minutes, (the house-surgeon's notes-say " ten to fifteen minutes,"-my own give "about a quarter of an hour,") when, about to desist, I fancied I observed a convulsive heave of the chest. This encouraged me to redouble my efforts, begging $\mathrm{Mr}$. Rackham at the same time to use brisk friction over the region of the heart. Warmth was ordered to the feet, \&c. ; irregular attempts at breathing soon followed, but they almost immediately flagged and censed. The windows of the ward were thrown open, the mother and nurses directed to stand off the bed, and taking full inspirations, I returned again and again to the charge, imitating as well as I was able natural respiration. I continued thus striving for at least three quarters of an hour, when sick from the mucus and stuff that had entered and adhered to my mouth, and exhuusted by my exertions, I had the delight of seeing the eyes and countenance regain expression, the breathing regularly performed, the pulse established at the wrist, and consciousness and sensibility restored. The boy noticed my attentions, recognized and kissed his mother, motioned for drink, and swallowed cold water as well as the injury to the mouth would permit. The tube was retained in the wound by threads carried behind the neck and tied, and the secretion which occasionally choked it up, was removed by the syringe or a feather a worsted comforter was thrown loosely over the neck, and the temperature of the ward warmed and regulated. Our little patient turned himself comfortably upon his side, and I, after waiting a little time, left the hospital, requesting to be furnished with a report during the evening, and promising to visit him at midnight.

During the evening I received the following accounts from Mr. Rackham, whose attention was unremitting. 8 o'clock. Vespere. "Your little patient has slept a little; the skin is moist and warm ; respiration through the tube easy ; has taken a little arrow-root."

Half-past 9 o'clock. "Some obstruction in the tube, which I have cleared; respiration quickened and becoming difficult; the powers of life failing, I have given a second enemr of arrowroot and brandy." Between eleven and twelve at night $I$ visited, and was sorry to observe the poor boy oppressed with a drowsy stupor, from which there was no difficulty for a time arousing him; the skin was deadly pale and bedewed with moisture; the pulse had no volume, and the breathing was hurried, and accompanied with a sonorous mucous rale. Desiring thoroughly to cleanse the clogged up tube, I removed it, but was directly obliged, owing to the threatenings of instant suffocation, to return it. Finding no relief from exhausting the tube and breathing apparatus of the frothy mucus which much obstructed them, and that the powers of life had now been flagged to the utmost, and being unable to devise further assistance, I left the case to Mr. Rackham, requesting him to keep the tube as clear as possible with a syringe, and to repeat the enema.

The boy from that time gradually sank, and at five o'clock in the morning, several hours after the operation of tracheotomy, " again died," the system being unable longer to withstand the shock of the loss of blood which it had received from so severe an injury.

The above case, related from. the notes of $\mathrm{Mr}$. Rackham, and those I penned at the time, and resenbling somewhat No. 3 of the cases detailed in the able paper of Mr. Cock, in the second number of the Medial Gazette for the present year, is offered to you for insertion at the suggestion of a deservedly influential nember of the Provincial Association. It affords additional confirmation, if any be needed, of the success that may attend well and perseveringly directed efforts at resuscitation in cases of asphyxia. During my house-surgeoncy, in 1834-5, at the Lynn Dispensary, I succeeded in re-animating two coal-porters immediately 
after immersion, but failed in several other cases, possibly from the means employed being persisted in for a too limited a period. In the present instance I was not less astonished than the by-standers, at observing the enlivening effect of a dose of warm breath on each occasion of the heart faltering, and the respiration flagging, or even ceasing altogether. The use of a less deteriorated air, or one to which a little oxygen had been added, would have been, as Dr. Clay remarks in the Medical Times of September, "very desirable if it could be procured ;" but I con. fes that the encouragement afforded in the above narrated case will in future, regardless of on over refined chemical physiology, induce me to pursue a similar course, and to be guided in my exertions, like Dr. Douglas, " by no measurement of time.

- Medical Gazette, December, 1812.

\section{UNIVERSITY COLLEGE HOSPITAL.}

\section{CASE OF CHRONIC INFLAMMATION OF THE BLADDER.}

(Reported by W. H. Colborne.)

William Woollams, a servant, aged 68 , married, was admitted into this hospital, August $27 \mathrm{th}, 1845$, under Dr. Williams, for asthma. The patient is of the middle height, lymphatic temperament, with a sallow complexion, and of tolerably regular habits, and has been accustomed to good living. Though he ha: suffered from severe colds occasionally for these last few years, be has not been compelled to keep his bed from illness since an attack of inflan:mation of the bowels thirty-eight years ago, until he was laid up by rheumatism, at the beginning of last winter, on recorering from which be caught a severe cold soon after Christmas, had a cough, and expectorated pellets of thick mucus; for this he applied at a dispensary and was relieved by the treatment adopted. In May he was again ill, and suffered from troublesome shortness of breathing with $n$ dry hacking cough, and was rery much weakened. In July he was tiken into King's College Hospital ; some ulcers of the legs co-existing with a varicose condition of the veins were there healed, and his cough and dyspnoea somewhat relieved; he left this hospital on August 13th, and his dyspr.ea became much worse. Has had gonorrhen several times during the earlier period of his life, and has been aware of having a stricture of the urethra for these last forty-two years, and for some time has required to have the catheter passed, from inability to make water; nothing, however, of a satisfactory account can be drawn out of him respecting the history of his urinary disorders, as he is very irritable, and his dyspnœa prevents much intelligible conversation.

Present condition. Is extremely weak, with an anxious expression of countenance, and his body is generally anasarcous. The difficulty of breathing prevents his lying down in bed, and obliges him to keep in the semi-erect posture; he experiences a constant pain at the epigastrium, much increased during the paroxysms of dyspncea, which recur about every ten minutes, and occasionally last for five or ten minutes; the shortness of breath is, however, very distressing between the paroxysms. Palse small, quick, and weak; he has no rigors nor increase of heat, no perspirations, skin cool; has a slight cough and expectorates some viscid mucus in sinall clots, mixed with some yellow purulent-looking imatter. Mouth rather dry; tongue furred and white; feels a slight thirst, appetite bad. The heart's action is extensively felt ; sounds clear; no murmur audible. On percussing the chest a general resonance is found in front, and the lower and posterior parts are much duller than is natural; breath-sound, whiffing, with some unco-crepitation; bowels costive; abdomen enlarged, with slight superficial fuctuation and some œdema of the walls. There is a little tenderness about the right kidney; frequent and painful micturition; urine scanty, high-coloured, specific gravity 1.017, alkaline, deposits a great quantity of brownish viscid mucus, aud contains a large proportion of albumen.

27 th. A blister was applied between the shoulders, and a draught with half a grain of extract of stramonium, fifteen drops of tincture of squill, and the same quantity of tincture of digitalis, giren thrice a diny ; the bowels being costive a pill of calomel, conium, and colocynth uras ordered at bed time.

28th. The blister has not risen; the passing of the catheter was called for last night.

29th. Bowels freely moved; urine deposits less mucus, specific gravity 1.020 , slightly acid, and shewed, on standing, a sediment, consisting of the triple phosphates and pus-globules.

The breathing became easier under this treatment. though he had a severe paroxysm of dyspncea on the night of the 2 nd of September; the urine became much less albuminous shewing only a slight quantity, but the deposit of ropy mucus was not diminished. On the 2nd September a draught of an ounce and a half of infusion of pareira, and twenty minims of tincture of henbane was substituted for his former draught, and croton oil was rubbed in on the back of the chest, and repented until it produced a thick crop of pustules.

9th. The following draught was substituted for the last :-

R. Potassii. Iodid, gr. iij.; Tinct. Scillæ., m. xx.; Liq. Potassæ, m. xx.; Tinct. Hyoscyami., dr. ss.; Mist, Acaciæ, dr.j.; Aquæ, oz. j. M.

The patient gradually improved until the 15 th, when he complained of severe pain in the lower part of the abdomien, and constant desire to make water, which passed only by drops; five ounces of high-coloured alkaline urine were drawn off.

On the 16th the pain was better, and his micturition tolerable easy. Three quarters of a grain of extract of belladonna was substituted for the tincture of henbane.

18th. Catheterism was again necessary; the urine contained the same mucus, a little albumen, and an excess of the phosphates.

On the 19th his asthma being unuch better, he was transferred to the care of Mr. Quain, to be treated for the disease of the urinary organs. He is now able to remain in a less erect position, has a constant desire to make water, which is voided with great pain and straining, depositing a great quantity of ropy viscid mucus, which adheres to the bottom of the vessel.

R. Infus. Buchu., oz. iss.; Tinct. Hyoscy. m. xx. Sit haust. ter die sumend.

20th. A catheter (No. 7) was passed, and alight 